\title{
Effects of $\mathrm{TiO}_{2} /$ Bentonite on the Pyrolysis Process of Oily Sludge
}

\author{
Feifei Wang*(**), Huan Zhang***, Mingming Du*, Jinling Li*, Penghui Yang*, Tao Yu*, Yijun Wang**** \\ and Chengtun $\mathbf{Q u}^{*}(* *) \dagger$ \\ *College of Chemistry and Chemical Engineering, Xi' an Shiyou University, Xi' an 710065, P. R. China \\ **State Key Laboratory of Petrochemical Pollution Control and Treatment, Beijing 102206, P. R.China \\ ***School of Chemistry and Chemical Engineering, Southwest Petroleum University, Chengdu 610500, P. R.China \\ ****Karamay City Sanda Testing and Analysis Co., Ltd, 834000, P.R.China \\ †Corresponding author: Chengtun Qu; xianquct@163.comm
}

Nat. Env. \& Poll. Tech.

Website: www.neptjournal.com

Received: 21-02-2020

Revised: $13-03-2020$

Accepted: 02-05-2020

Key Words:

Oily sludge

Catalyst

$\mathrm{TiO}_{2} /$ bentonite

Catalytic pyrolysis

\section{ABSTRACT}

Oil sludge is one of the major industrial solid wastes from petroleum production and refining. Implementing the harmless and resource treatment of oily sludge is an urgent problem to be solved. In this paper, $\mathrm{TiO}_{2}$ /bentonite was prepared by sol-gel method, which was characterized by scanning electron microscope (SEM), transmission electron microscope (TEM), X-ray diffraction (XRD), X-ray photoelectron spectroscopy (XPS) and infrared spectroscopy (FT-IR), and then used in the pyrolysis process of oily sludge. The addition of $\mathrm{TiO}_{2}$ /bentonite give the best quality of pyrolysis oil; maximum oil recovery was achieved when setting the pyrolysis condition at $420^{\circ} \mathrm{C}$ for final pyrolysis temperature, $3 \mathrm{~h}$ for reaction time, $10^{\circ} \mathrm{C} / \mathrm{min}$ for heating rate, $100 \mathrm{~mL} / \mathrm{min}$ for nitrogen flow rate and $1 \%$ for catalyst dosage. Compared with the non-catalyst, oil recovery rate can be increased from $76.06 \%$ to $84.16 \%$, the oil content of the residue decreased from $2.23 \%$ to $1.36 \%$. The pyrolysis recovery oil was analysed by GC-MC, and the fractions of pyrolysis oil $\mathrm{C}_{6}-\mathrm{C}_{15}$ were increased by $27.84 \%$. This shows that the addition of $\mathrm{TiO}_{2}$ /bentonite decreased the carbon residue, increased oil recovery and improved product quality.

\section{INTRODUCTION}

Oil sludge is one of the major industrial solid wastes from petroleum production and refining process (Mrayyan \& Battikhi 2005, Agar et al. 2018 ), which is increasing quickly (Zhao et al. 2019, Wang et al. 2019) with the rapid development of economy, and it have been listed to the Directory of National Hazardous Waste as one of the most hazardous solid wastes. If oily sludge is discharged into the environment directly without reasonable treatment, it is not only harmful to the surrounding environment, animal and plant health, but also is a waste of resources because the containing of some content oil (Gong et al. 2018). Many countries are paying more attention to sewage sludge effective treatment and recycling, while the low-temperature pyrolysis of sludge is a new sludge treatment technology which developed in the recent years (Folgueras et al. 2013, Botella et al. 2015). The pyrolysis of the sludge is an emerging process technology, which is a promising alternative for sludge treatment in terms of treatment efficiency pollution reduction (Wang et al. 2018, Wang et al. 2017, Tang et al. 2018) and energy and resource recovery. But the quality of the oil obtained from the pyrolysis of sewage sludge cannot be used directly, the upgrading of sludge oil is indispensable.
To improve the quality of oil and enhance oil recovery, a series of studies on the addition of catalysts or additives during the pyrolysis of sludge were carried out. The addition of catalyst in the pyrolysis process of oily sludge time, improve the pyrolysis efficiency and decrease the amount of solid residue (Yang et al. 2018, Lin et al. 2017, Lin et al. 2019, Liu et al. 2015). Many scholars (Wang et al. 2015, Wang et al. 2008, Shie et al. 2004) found that the addition of catalyst can improve the yield and quality of oil products from oil sludge during the pyrolysis process. In recent years, an intense effort has been focused on the preparation of metal-oxide nanocrystals owing to their markedly different physical and chemical properties with respect to bulk materials. Particularly, titanium dioxide has been studied extensively as a photocatalyst to deal with environmental pollution, water purification, wastewater treatment, hazardous waste control, and air purification, due to its good characteristics of chemical stability, endurance, thin-film transparency and lower production costs. However, there are certain shortcomings associated with conventional $\mathrm{TiO}_{2}$ powders catalysts, including $\mathrm{TiO}_{2}$ is difficult to recover in the catalytic process, easy to lose, easy to agglomerate, and its application is limited. So the $\mathrm{TiO}_{2}$ exhibits a poor catalytic can reduce the pyrolysis temperature, shorten the reaction 
activity to non-polar organic compounds, resulting in limited catalytic efficiency. To enhance the catalytic activity onto the catalyst surface, various porous solid supports such as zeolite, silica and clay are utilized to support $\mathrm{TiO}_{2}$. For this reason, $\mathrm{TiO}_{2}$ can be supported on some inexpensive and readily available catalyst supports with good adsorption and large specific surface area to make the supported catalysts. On the one hand, $\mathrm{TiO}_{2}$ can be immobilized, and on the other hand, the layered molecular structure of bentonite can be modified to increase the contact area between the catalyst and the oily sludge, and play a role of synergistic catalysis, so as to improve the catalytic performance. Xiao et al. (2012) studied the pyrolysis characteristics and pyrolysis kinetics of paper sludge before and after the addition of $\mathrm{MnO}_{2}, \mathrm{Al}_{2} \mathrm{O}_{3}$, $\mathrm{MgO}, \mathrm{Fe}_{2} \mathrm{O}_{3}, \mathrm{CuO}$ or $\mathrm{CaO}$ by thermograin-analysis. The results showed that the influence of these metal oxides on the pyrolysis of sludge was mainly in the middle and high temperature stage. Shao et al. (2010) studied the catalytic effect of $\mathrm{Fe}_{2} \mathrm{O}_{3}, \mathrm{ZnO}, \mathrm{Al}_{2} \mathrm{O}_{3}, \mathrm{CaO}$ and $\mathrm{TiO}_{2}$ on sludge pyrolysis, and found that these metal oxides could promote the decomposition of volatilization in sludge at the initial stage of the reaction. Since the bentonite has a significant effect on the pyrolysis of the low temperature zone during the pyrolysis of the oily sludge, the catalytic effect on the pyrolysis of the medium and high temperature zone is poor. Therefore, the bentonite is combined with the $\mathrm{TiO}_{2}$ that plays a catalytic role in the middle and high temperature areas to play a synergistic catalytic role. The main objectives of this study were: (1) To evaluate the influence of $\mathrm{TiO}_{2} /$ bentonite on the quality of oil products; (2) To evaluate the effect of $\mathrm{TiO}_{2} /$ bentonite on the oil recovery rate of the pyrolysis process.

\section{MATERIALS AND METHODS}

\section{Materials}

The oily sludge sample used in this study was derived from the bottom sludge of an oil-separating tank in the Shanbei oil field Branch Company, China. The oily sludge sample appears black and possesses poor settling ability. The composition (including oil content and water content of sludge) of the oily sludge has been analysed and listed in Table 1. The water content was determined by ASTM-D95-13 (Lin et al. 2019) and oil content of sludge was determined by Soxhlet extraction using petroleum ether as a solvent. Tetrabutyl titanate, anhydrous ethanol, distilled water, acetic acid, bentonite and petroleum ether were all analytically pure reagents. The experimental water used was deionized water. All chemicals have been used as received without further purification.

\section{Preparation of Catalysts}

In this study, the supported catalyst was prepared by SolGel method based on bentonite as matrix material (Yao et al. 2012, Cao et al. 2010, Li et al. 2007, Chen et al. 2009). The preparation process is shown in Fig. 1. The precursor was tetrabutyl titanate $\left(\mathrm{Ti}\left(\mathrm{OC}_{4} \mathrm{H}_{9}\right)_{4}, 97 \%\right)$. $\mathrm{Ti}\left(\mathrm{OC}_{4} \mathrm{H}_{9}\right)_{4}$ was dissolved in anhydrous ethanol, and then mixed with acetic acid and deionized water under stirring. To avoid rapid precipitation during polycondensation and formation of unstable colloidal sols, the hydrolysing water was homogeneously released by the esterification of ethanol and acetic acid (Zhao et al. 2009). The clear solution was stabilized by stirring at ambient temperature for $1 \mathrm{~h}$, then placed and

Table 1: Chemical characteristics of oily sludge.

\begin{tabular}{|c|c|c|c|c|c|c|c|c|}
\hline \multicolumn{6}{|c|}{ Element composition (\%) } & \multirow[t]{2}{*}{ Oil content/\% } & \multirow[t]{2}{*}{ Water content $/ \%$} & \multirow[t]{2}{*}{ Calorific value $(\mathrm{kJ} / \mathrm{kg})$} \\
\hline $\mathrm{C}(\%)$ & $\mathrm{N}(\%)$ & $\mathrm{H}(\%)$ & $\mathrm{S}(\%)$ & $\mathrm{C} / \mathrm{N}$ & $\mathrm{C} / \mathrm{H}$ & & & \\
\hline 21.63 & 1.45 & 4.25 & 2.36 & 14.949 & 5.086 & 18.67 & 11.20 & 12813.69 \\
\hline
\end{tabular}

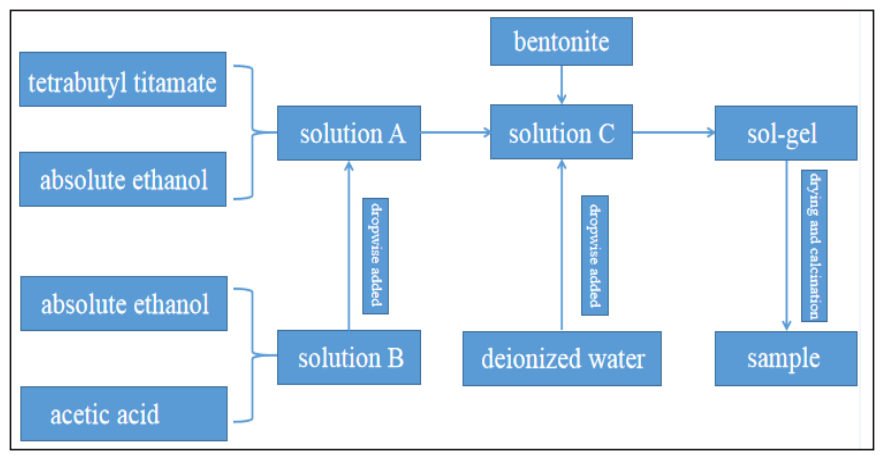

Fig. 1: The flow chart to prepare $\mathrm{TiO}_{2}$ /bentonite catalysts. 
aged for $24 \mathrm{~h}$. Subsequently, the transparent sol was dried at $150^{\circ} \mathrm{C}$, and then calcined to burn off hydrocarbons. The sample was crushed into powder in a mortar at last. Liu et al. (2009) studied the effect of calcination temperature on the structure of titanium dioxide photocatalyst. When the calcination temperature is $500-550^{\circ} \mathrm{C}$, the development of $\mathrm{TiO}_{2}$ crystal is gradually complete, and the lattice structure tends to be perfect, which is an anatase crystal phase with a catalytic effect. Therefore, it is selected to calcine at $500^{\circ} \mathrm{C}$ for 3 hours. The white powder obtained is $\mathrm{TiO}_{2} /$ bentonite, which is recorded as $\mathrm{TiO}_{2} /$ bentonite (1) $(n \mathrm{Si}: n \mathrm{Ti}=8: 1) . \mathrm{TiO}_{2} /$ bentonite (2) $(n \mathrm{Si}: n \mathrm{Ti}=4: 1)$ and $\mathrm{TiO}_{2} /$ bentonite (3) $(n \mathrm{Si}: n \mathrm{Ti}$ $=1: 1$ ) was synthesized by changing the ratio of butyl titanate to bentonite in the same way.

\section{Characterization of Catalysts}

The surface morphology was investigated by scanning electron microscopy (SEM) using a JEOL JSM 6400 electronic microscope equipped with an energy-dispersive X-ray (EDX) detector (eXL10 from Link Analytical). X-ray diffraction (XRD) patterns were recorded by an Empyrean X-ray diffractometer with $\mathrm{Cu} \mathrm{Ka}$ radiation. X-ray photoelectron spectroscopy (XPS) measurements were performed using a Thermon ESCAlab 250 spectrometer with $\mathrm{Al} \mathrm{Ka}$ radiation as an excitation source. In order to analyze the surface chemical state of the obtained samples, the publicly available XPSPEAK v4.1 software package was used to perform a curve fitting of the raw data corresponding to the Ti2p high-resolution spectra. Fourier transform infrared (FTIR) spectra were obtained in a Bruker Vertex 70 spectrometer, with $\mathrm{KBr}$ pellets and a resolution of $2 \mathrm{~cm}^{-1}$. Nitrogen adsorption isotherms were measured using a Micromeritics ASAP 2020 analyser. Samples were degassed at $300^{\circ} \mathrm{C}$ and $5 \times 10^{-3}$ torr vacuum. The surface area was obtained by the BET method, and t-plot external area, micropore area, and micropore volume were also calculated.

\section{Thermogravimetric Analysis}

The thermogravimetric analysis (TG/DTG) was performed with a DSC/DTA-TG STA449F3 (Germany) thermogravimetric analyser. The initial mass of the samples was kept between 5 and $10 \mathrm{mg}$ to avoid any possible effect on mass and heat transfer during the decomposition process. The samples were heated from 25 to $900^{\circ} \mathrm{C}$ at a heating rate of $10^{\circ} \mathrm{C} / \mathrm{min}$ for solving the compensation effect under a nitrogen atmosphere with a flow rate of $20 \mathrm{~mL} \mathrm{~min}^{-1}$ to investigate the effect of adding different catalysts on pyrolysis.

\section{Catalytic Cracking Tests}

Experimental method for pyrolysis of oily sludge: the catalyst was mixed with oily sludge in a certain proportion and then placed in a pyrolysis furnace for pyrolysis. The performance of the catalyst was studied according to the analysis of pyrolysis products and the recovery rate of pyrolysis oil.

\section{Products Analysis}

The study examined the liquid products and solid products obtained by catalytic pyrolysis. The analysis of liquid phase pyrolysis products: composition of the liquid phase of pyrolysis products was explored by GC-MS (Yang et al. 2014) and four components of pyrolysis liquid phase products were determined by NB/SH/T0509-2010 oil bitumen four-component determination method (Zhang et al. 2009). The analysis of pyrolysis solid products: elemental analysis, oil content and calorific value of pyrolysis residue.

\section{RESULTS AND DISCUSSION}

\section{Catalysts Characterization}

Morphological feature: The SEM images are typical of the catalyst materials synthesized during this study. The SEM analysis of bentonite, $\mathrm{TiO}_{2}$ /bentonite(1), $\mathrm{TiO}_{2}$ /bentonite(2) and $\mathrm{TiO}_{2}$ /bentonite(3) are shown in Fig. 2. The surface of bentonite (a) was tight and the porosity was small, while the surfaces of $\mathrm{TiO}_{2}$ /bentonite(1) (b) was loose with more pores, the surface of $\mathrm{TiO}_{2} /$ bentonite(2) (c) was loose with more pores and small granules, the surface of $\mathrm{TiO}_{2}$ /bentonite(3) (d) was tight with small granules. The reason for this phenomenon is that the bentonite after loading titanium dioxide changes its morphology, increases the porosity and increases the specific surface area.

The EDS analysis of bentonite, $\mathrm{TiO}_{2}$ /bentonite(1), $\mathrm{TiO}_{2}$ /bentonite(2) and $\mathrm{TiO}_{2}$ /bentonite(3) are shown in Fig. 3 . It can be seen that the content of Ti appeared compared with bentonite, which indicates that $\mathrm{Ti}$ was loaded onto bentonite. In addition, titanium content of $\mathrm{TiO}_{2}$ /bentonite(2) is greater than that of $\mathrm{TiO}_{2}$ /bentonite(1) and titanium content of $\mathrm{TiO}_{2}$ /bentonite(3) is greater than that of $\mathrm{TiO}_{2}$ /bentonite(2). From Fig. 3, the bentonite contains other elements, such as Al, Si and so on. The presence of these elements can promote the pyrolysis of sludge, thus actively promoting the research and development of pyrolysis catalysts for oily sludge.

\section{Infrared Spectral Analysis}

It also can be seen the O-H stretching vibration of adsorbed water in the interlayer of montmorillonite structure nearby $3439 \mathrm{~cm}^{-1}$ (Zhu et al. 2012). It had stretching vibration band of $\mathrm{O}-\mathrm{H}$ near $1642 \mathrm{~cm}^{-1}$, and the peak near $1035 \mathrm{~cm}^{-1}$ attributed to the asymmetry bending stretching of Si-O-Si. The bending vibration absorption peak of Si-O-Al near 519 


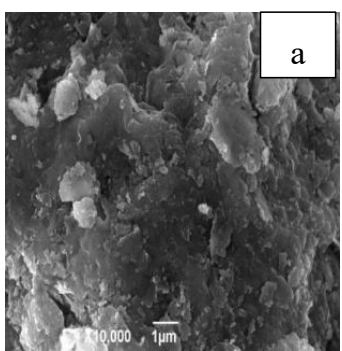

a. bentonite

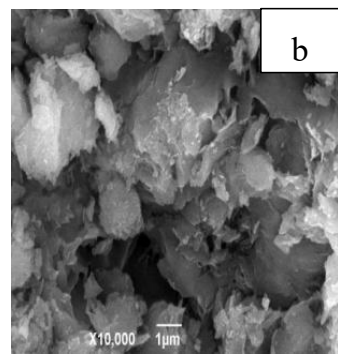

b. $\mathrm{TiO}_{2} /$ bentonite(1)

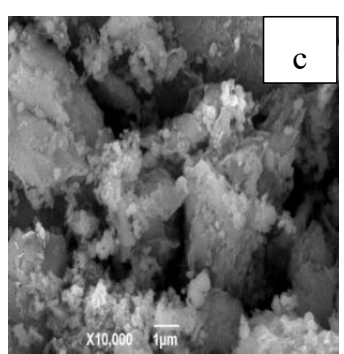

c. $\mathrm{TiO}_{2} /$ bentonite $(2)$

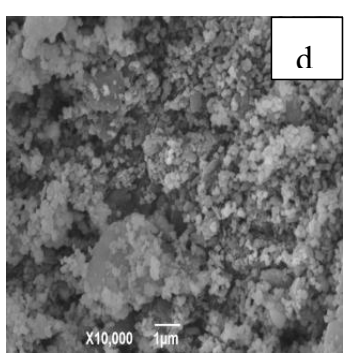

c. $\mathrm{TiO}_{2}$ /bentonite(3)

Fig. 2: SEM analysis of bentonite, $\mathrm{TiO}_{2}$ /bentonite(1), $\mathrm{TiO}_{2}$ /bentonite(2) and $\mathrm{TiO}_{2}$ /bentonite(3).

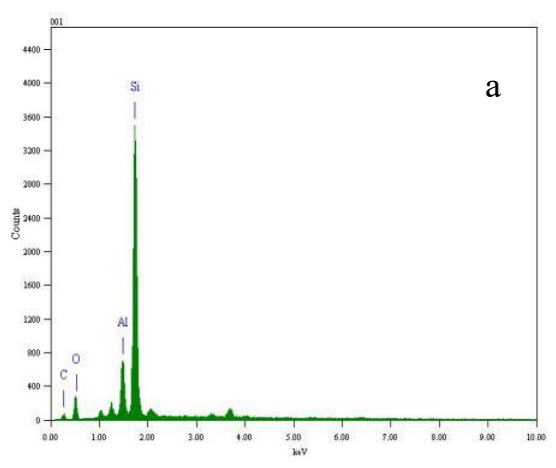

a. bentonite

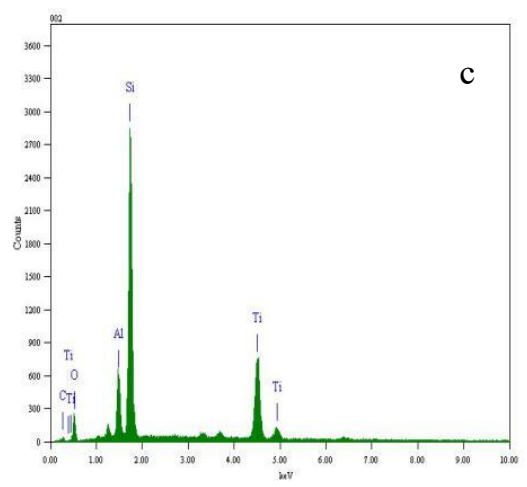

c. $\mathrm{TiO}_{2}$ /bentonite(2)

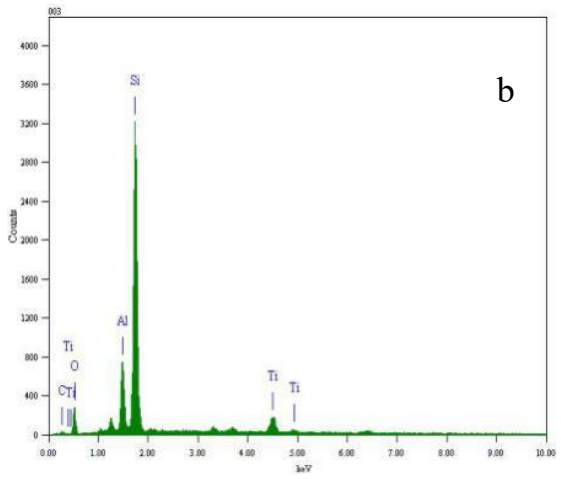

b. $\mathrm{TiO}_{2}$ /bentonite(1)

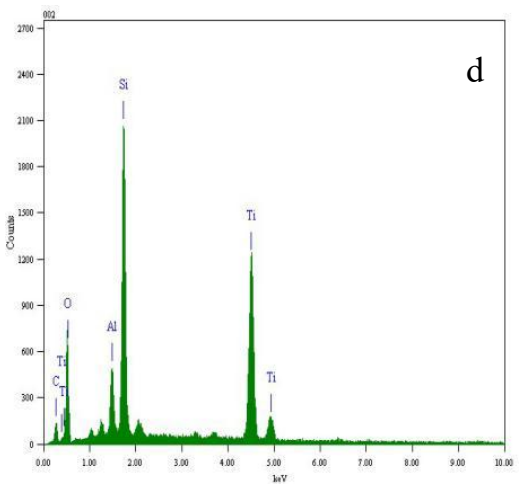

d. $\mathrm{TiO}_{2} /$ bentonite(3)

Fig. 3: EDS analysis of bentonite, $\mathrm{TiO}_{2}$ /bentonite(1), $\mathrm{TiO}_{2}$ /bentonite(2) and $\mathrm{TiO}_{2}$ /bentonite(3).

$\mathrm{cm}^{-1}$, the peak near $1407 \mathrm{~cm}^{-1}$ is attributable to the bending stretching of $\mathrm{Si}-\mathrm{O}-\mathrm{Si}$. The peak near $1035 \mathrm{~cm}^{-1}$ is attributed to the asymmetry bending stretching of Si-O-Si. It can be seen that $\mathrm{TiO}_{2} /$ bentonite(1) composite (Fig. 4b ), $\mathrm{TiO}_{2} /$ bentonite(2) composite (Fig. 4c ) and $\mathrm{TiO}_{2} /$ bentonite(3) (Fig. $4 \mathrm{~d}$ ) the peak near 600 900 $\mathrm{cm}^{-1}$ has obvious absorption peak. This is the absorption peak of Ti-O bond of $\mathrm{TiO}_{2}(\mathrm{Liu}$ et al. 2011). The results revealed that $\mathrm{TiO}_{2}$ was inserted into bentonite's layers.

\section{X-ray Diffraction Pattern Characteristics}

XRD patterns of the bentonite, $\mathrm{TiO}_{2} /$ bentonite(1), $\mathrm{TiO}_{2} /$ bentonite(2) and $\mathrm{TiO}_{2}$ /bentonite(3) were obtained as shown in Fig. 5. The anatase phase of the corresponding diffraction peaks appeared at $2 \theta=25.2^{\circ}, 37.8^{\circ}, 48.1^{\circ}$, and $55.2^{\circ}$ in both the $\mathrm{TiO}_{2}$ /bentonite(1), $\mathrm{TiO}_{2} /$ bentonite(2) and $\mathrm{TiO}_{2} /$ bentonite(3) samples (Yu et al. 2017). The d (001) plane diffraction peaks of $\mathrm{TiO}_{2}$ /bentonite(1), $\mathrm{TiO}_{2} /$ bentonite(2) and 


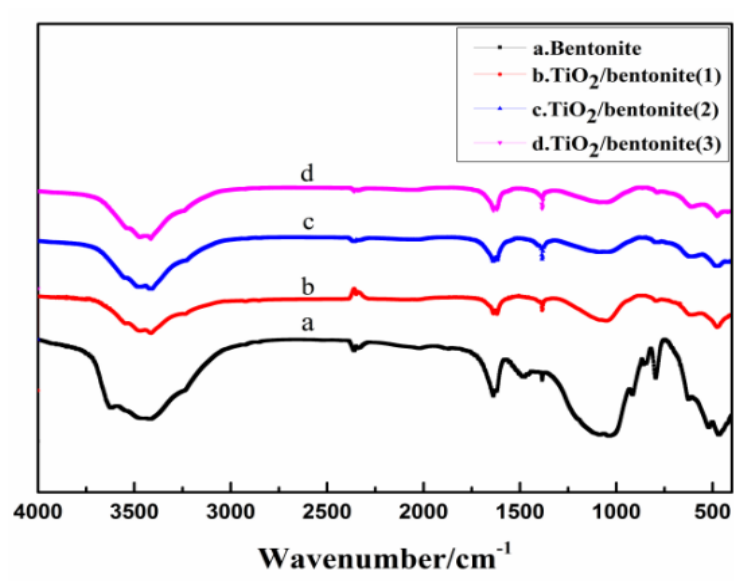

Fig. 4: FTIR of the bentonite, $\mathrm{TiO}_{2} /$ bentonite(1), $\mathrm{TiO}_{2} /$ bentonite(2) and $\mathrm{TiO}_{2}$ /bentonite(3).

$\mathrm{TiO}_{2}$ /bentonite(3), i.e. the position and intensity of the first peak have changed obviously. The intensity of the diffraction peak is weaker than that of bentonite. At the same time, compared with the bentonite, the d(001) diffraction angles of $\mathrm{TiO}_{2}$ /bentonite(1), $\mathrm{TiO}_{2}$ /bentonite(2) and $\mathrm{TiO}_{2}$ /bentonite(3) increased. It can be seen from the Bragg equation $n \lambda=$ $2 \mathrm{~d} \sin \theta$ that the layer spacing $\mathrm{d}(001)$ of catalyst is smaller than that of bentonite (Yang 2012). This phenomenon is caused by the replacement of calcium hydrate between bentonite layers by titanium ions. The results revealed that $\mathrm{TiO}_{2}$ were inserted into bentonite's layers.

\section{Specific Surface Area and Aperture Determination}

The specific surface area is one of the important parameters in catalysts. This characteristic must be taken into account

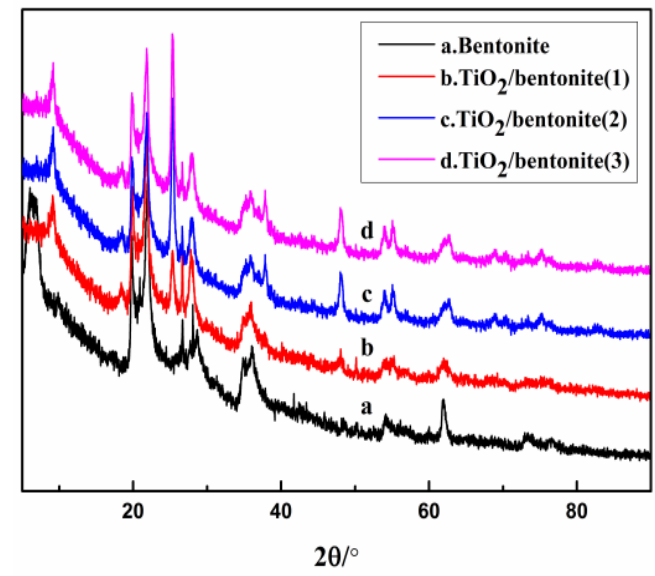

Fig. 5: XRD of the bentonite, $\mathrm{TiO}_{2}$ /bentonite(1), $\mathrm{TiO}_{2} /$ bentonite(2) and $\mathrm{TiO}_{2}$ /bentonite(3).

especially in the case of supported catalysts (Cecílio et al. 2004, Yahya \& Ngadi 2016). The $\mathrm{N}_{2}$ adsorption/desorption isotherms for the $\mathrm{TiO}_{2}$ /bentonite(1), $\mathrm{TiO}_{2}$ /bentonite(2) and $\mathrm{TiO}_{2}$ /bentonite(3) are shown in Fig. 6(a). It should, however, be noted that in all the isotherms hysteresis is present in the low relative pressure range at $\mathrm{p} / \mathrm{p}^{\mathrm{o}}>0.4$, due to the phenomenon of capillary condensation in the adsorption process, the adsorption isotherm and the desorption isotherm do not coincide, resulting in a hysteresis lag, and the desorption isotherm is above the adsorption isotherm, resulting in a retention ring; and also well-developed hysteresis loops which testify to the development of the mesopore structure. It can be seen from Table 2 that the specific surface area of the bentonite increased after loading, the specific surface area increased from $47.69 \mathrm{~m}^{2} / \mathrm{g}$ to 67.76

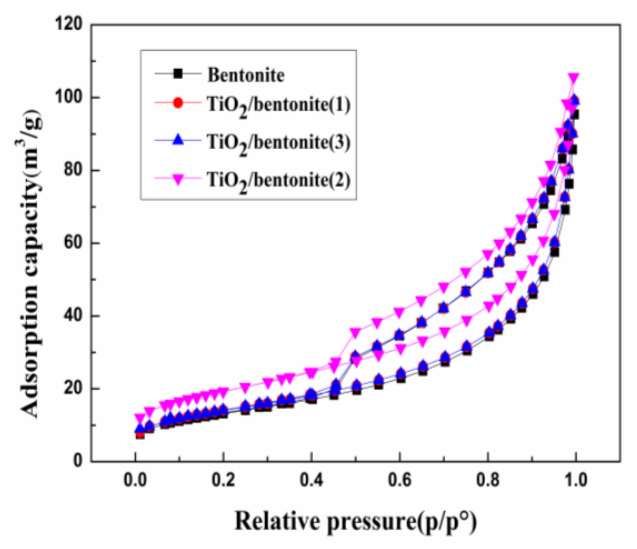

a. Isothermal adsorption curve.

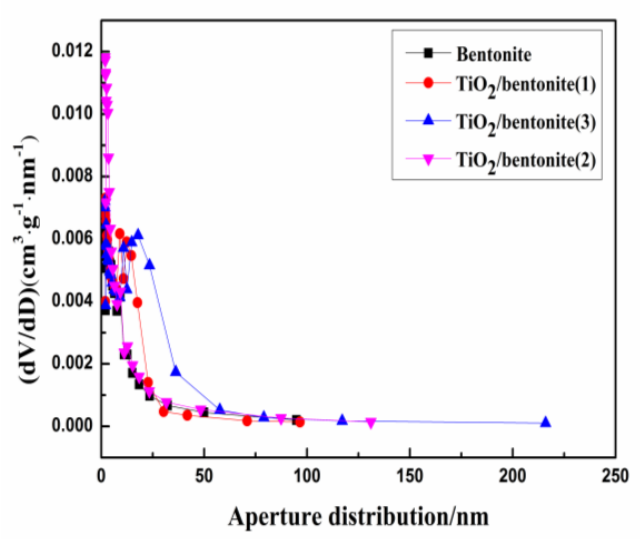

b. Aperture distribution curve.

Fig. 6: Isothermal adsorption curve and aperture distribution curve of the bentonite, $\mathrm{TiO}_{2} /$ bentonite(1), $\mathrm{TiO}_{2} /$ bentonite(2) and $\mathrm{TiO}_{2} /$ bentonite(3). 
Table 2: Mesopore surface area and pore volume results of catalysts.

\begin{tabular}{|llll|}
\hline & $\begin{array}{l}\mathrm{S}_{\text {mes }} \\
\left(\mathrm{m}^{2} / \mathrm{g}\right)\end{array}$ & $\begin{array}{l}\mathrm{V}_{\text {mes }} \\
\left(\mathrm{cm}^{3} / \mathrm{g}\right)\end{array}$ & $\begin{array}{l}\text { BJH average } \\
\text { aperture }(\AA)\end{array}$ \\
\hline Bentonite & 47.69 & 0.13 & 125 \\
$\mathrm{TiO}_{2}$ /bentonite (1) & 50.01 & 0.14 & 115.78 \\
$\mathrm{TiO}_{2}$ /bentonite (2) & 67.76 & 0.18 & 95.60 \\
$\mathrm{TiO}_{2}$ /bentonite (3) & 55.17 & 0.16 & 110.14 \\
\hline
\end{tabular}

$\mathrm{m}^{2} / \mathrm{g}$, and the specific surface area of $\mathrm{TiO}_{2} /$ bentonite(2) was larger than that of $\mathrm{TiO}_{2}$ /bentonite (1), $\mathrm{TiO}_{2}$ /bentonite(2) and $\mathrm{TiO}_{2}$ /bentonite(3). What is more, $\mathrm{TiO}_{2} /$ modified residue has higher $\mathrm{V}_{\text {mes }}\left(0.18 \mathrm{~cm}^{3} / \mathrm{g}\right)$ and $\mathrm{S}_{\text {mes }}\left(67.76 \mathrm{~m}^{2} / \mathrm{g}\right)$ according to Table 2, this is the reason why $\mathrm{TiO}_{2} /$ bentonite(2) possesses superior catalytic activity towards other kinds of catalysts. The $\mathrm{V}_{\text {mes }}$ and $\mathrm{S}_{\text {mes }}$ of catalysts prepared are also consistent with their catalytic activity. Because the surface morphology of bentonite changes greatly after loading, from a smooth and compact structure to an increase in porosity and a loose layer structure, the specific surface area increases. At the same time, the bentonite support could disperse the catalyst, increase the surface-active area of the catalyst. The increase of specific surface area will increase the contact area between the catalyst and oily sludge, thus improving its catalytic performance.

\section{Analysis of X-ray Photoelectron Spectroscopy (XPS)}

XPS analysis was carried out to investigate the surface/interface chemical states of the samples. In this paper, the valence

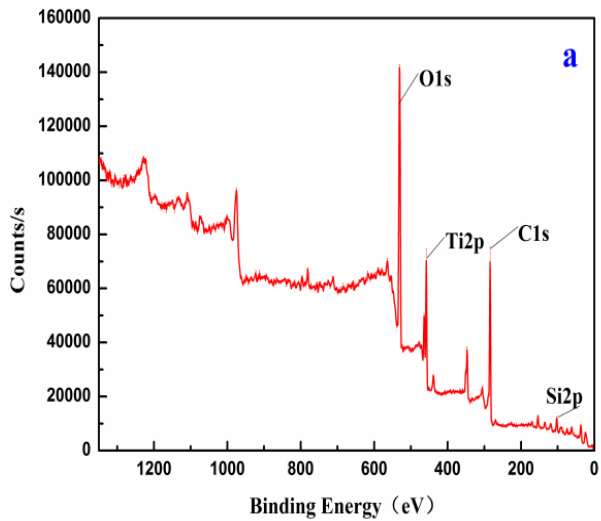

of titanium in $\mathrm{TiO}_{2}$ /bentonite supported catalyst is judged by XPS analysis. Full spectra of X-ray photoelectron spectroscopy of (a) $\mathrm{TiO}_{2}$ /bentonite(2) is shown in Fig. 7. Besides, a Ti2p peak located at $458.9 \mathrm{eV}$ is observed in Fig. 7. This result provides further evidence that $\mathrm{TiO}_{2}$ was successfully coated on the residue surface. The high-resolution XPS spectra of the Ti2p region is shown in Fig. 7(b). The peaks located at $458.9 \mathrm{eV}$ and $464.9 \mathrm{eV}$ correspond to the Ti2p3/2 and Ti2p $1 / 2$ binding energy regions, respectively (An et al. 2018, Wu et al. 2013). The results show that titanium exists in the catalyst with $\mathrm{Ti}^{4+}$, and titanium exists in the form of $\mathrm{TiO}_{2}$ in the composite catalyst.

\section{Effect of Catalyst on Pyrolysis Performance of Oily Sludge}

Effect of catalyst species on pyrolysis treatment: When the pyrolysis time was $4 \mathrm{~h}$, the pyrolysis temperature was $450^{\circ} \mathrm{C}$, the heating rate was $10^{\circ} \mathrm{C} / \mathrm{min}$, the nitrogen flow rate was $100 \mathrm{~mL} / \mathrm{min}$. Pyrolysis experiments were carried out with the addition of $1 \%$ of the two catalysts. Experimental results are given in Table 3.

It can be seen from Table 3 that the oil recovery rate of the bentonite and loaded bentonite is higher than that without the catalyst. And the catalytic effect of $\mathrm{TiO}_{2} /$ bentonite(2) is better than that of $\mathrm{TiO}_{2} /$ bentonite(1) and $\mathrm{TiO}_{2} /$ bentonite(1). Because the specific surface area of $\mathrm{TiO}_{2}$ /bentonite(2) was larger than that of $\mathrm{TiO}_{2}$ /bentonite(1) and $\mathrm{TiO}_{2}$ /bentonite(3), its catalytic effect is better. The prepared supported catalyst

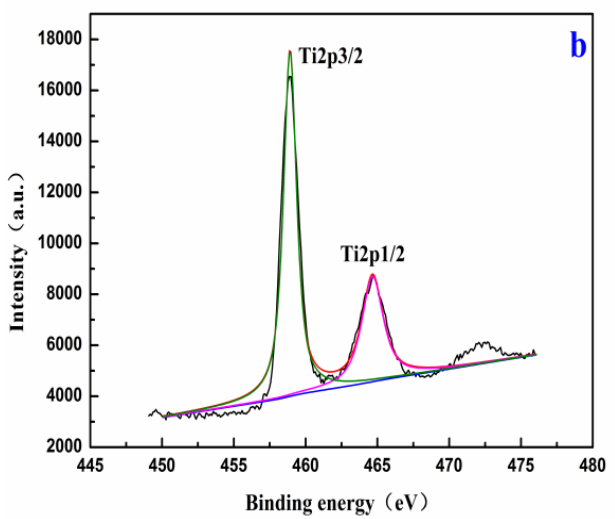

Fig. 7: XPS survey spectra of (a) $\mathrm{TiO}_{2} /$ bentonite(2); High-resolution $\mathrm{Ti} 2 p$ spectra of (b) $\mathrm{TiO}_{2} /$ bentonite(2).

Table 3: Effect of catalyst species on the recovery of pyrolysis oil.

\begin{tabular}{|llllll|}
\hline Catalyst species & Non- catalyst & Bentonite & $\mathrm{TiO}_{2} /$ bentonite $(1)$ & $\mathrm{TiO}_{2} /$ bentonite $(2)$ & $\mathrm{TiO}_{2} /$ bentonite $(3)$ \\
\hline Oily sludge quantity $(\mathrm{g})$ & 20.07 & 20.04 & 20.03 & 20.05 & 20.07 \\
Oil recovery quantity $(\mathrm{g})$ & 2.85 & 2.94 & 3.08 & 3.15 & 3.10 \\
Oil recovery rate $(\%)$ & 76.06 & 78.61 & 82.35 & 84.16 & 82.73 \\
\hline
\end{tabular}


$\left(\mathrm{TiO}_{2} /\right.$ bentonite) can increase the number of the active sites of catalyst and enhance the catalytic activity. The specific surface area of catalyst increases, which increases the contact area between the catalyst and oily sludge and promotes the pyrolysis of oily sludge. This is consistent with the mesopore surface area and pore volume results of catalysts.

\section{Thermogravimetric Analysis}

To detect the catalytic effect of the catalyst on the pyrolysis of oily sludge, the catalyst was added to the oily sludge in a certain proportion for thermal weight analysis. Thermogravimetric analysis has been an interesting and useful analytical technique for the characterization of different organic products such as pitches, sewage sludges and other waste materials (Méndez et al. 2005). Thermogravimetric analysis is an important method to study the characteristics of sludge weight loss, which is of great significance to explore the reasonable reaction mechanism and kinetic parameters. The thermogravimetric data (TG) curves and first derivative data curves (DTG) of raw sludge and $\mathrm{TiO}_{2}$ /bentonite (2) at $10^{\circ} \mathrm{C} / \mathrm{min}$ are shown in Fig. 8. As illustrated in Fig. 8(b), three peaks were identified in the DTG curves, leading to the partition of these thermogravimetric curves. The corresponding DTG curves were derived from the first derivative of the TG curves. It can be found that three peaks appeared in the DTG curve of oily sludge, the temperature ranges of which were region $\mathrm{I}\left(25-150^{\circ} \mathrm{C}\right)$, region $\mathrm{II}\left(150-450^{\circ} \mathrm{C}\right)$, region $\operatorname{III}\left(450-700^{\circ} \mathrm{C}\right)$, respectively. The weight loss of oily sludge in the first region was attributed to the evaporation of adsorbed water from the surface of the sludge particles, while the decomposition of sludge components was responsible for the weight loss in the other

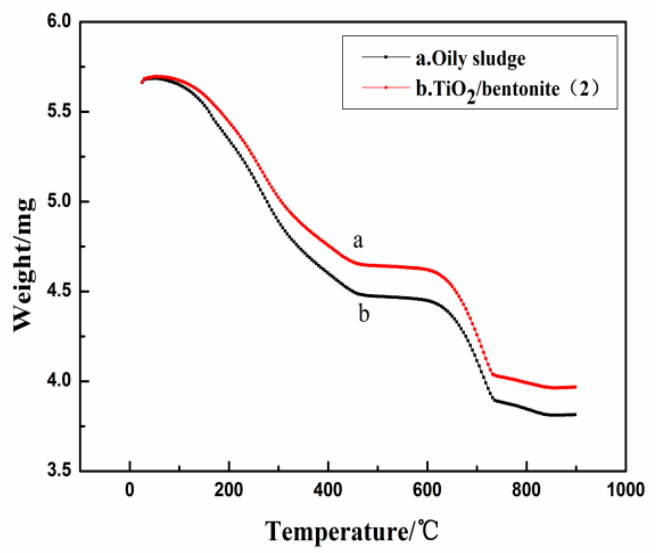

(a) TG curve two regions (Tang et al. 2018, Hayhurst 2013). More than $70 \%$ of the overall weight loss, as depicted in Fig. 8(a) occurred when the temperature was heated up from $25^{\circ} \mathrm{C}$ to $700^{\circ} \mathrm{C}$, which is generally the highest temperature applied for sludge pyrolysis in practice (Tang et al. 2017). It can be seen from the Fig. 8(a), that the total weightlessness is affected by the added catalyst, and the addition of the catalyst increases the weightlessness. When the temperature was increased further, the weight loss of $\mathrm{TiO}_{2}$ /bentonite(2)-blended sludge was appreciably larger when compared to that of the oily sludge and $\mathrm{TiO}_{2}$ /bentonite(1)-blended sludge. The results show that the addition of catalyst promotes the pyrolysis of oily sludge. This result is consistent with the previous characterization. The theory of carbonium ion explains the reaction mechanism of $\mathrm{TiO}_{2}$ /bentonite(2) catalytic cracking. A carbonium ion is a hydrocarbon ion formed by carbon lacking a pair of valence electrons. The carbonium ion is generated by obtaining a hydrogen ion $\mathrm{H}^{+}$from an olefin molecule, as shown in formula (1). The carbonium ion theory illustrates the role of the catalyst, which provides $\mathrm{H}^{+}$ on the catalyst surface. The hydrocarbon can react by the way of forming carbonium ion so that the activation energy of the reaction can be reduced and the reaction rate can be increased.

$$
\mathrm{C}_{\mathrm{n}} \mathrm{H}_{2 \mathrm{n}}+\mathrm{H}^{+} \rightarrow \mathrm{C}_{\mathrm{n}} \mathrm{H}^{+}{ }_{2 \mathrm{n}+1}
$$

\section{Effect of Catalyst on Pyrolysis Conditions of Oily Sludge}

The effect of the amount of catalyst on the oil recovery rate of pyrolysis process: When the pyrolysis time was $4 \mathrm{~h}$, the pyrolysis temperature $450^{\circ} \mathrm{C}$, the heating rate $10^{\circ} \mathrm{C} / \mathrm{min}$ and the nitrogen flow rate $100 \mathrm{~mL} / \mathrm{min}$, the effect

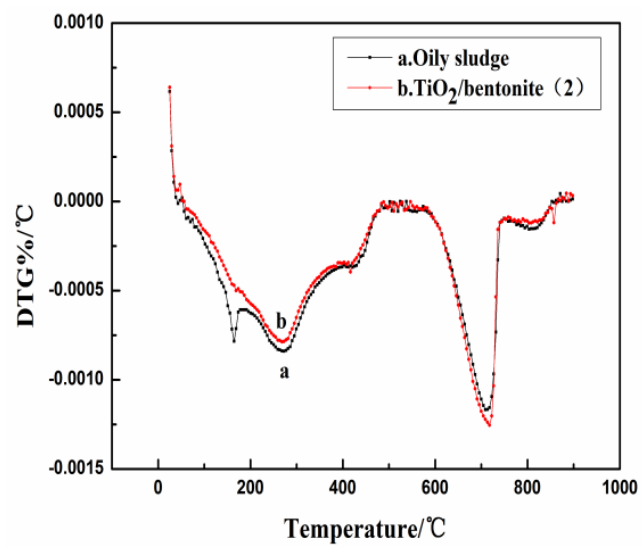

(b) DTG curve

Fig. 8: Thermogravimetric analysis of the oily sludge and $\mathrm{TiO}_{2}$ /bentonite(2). 


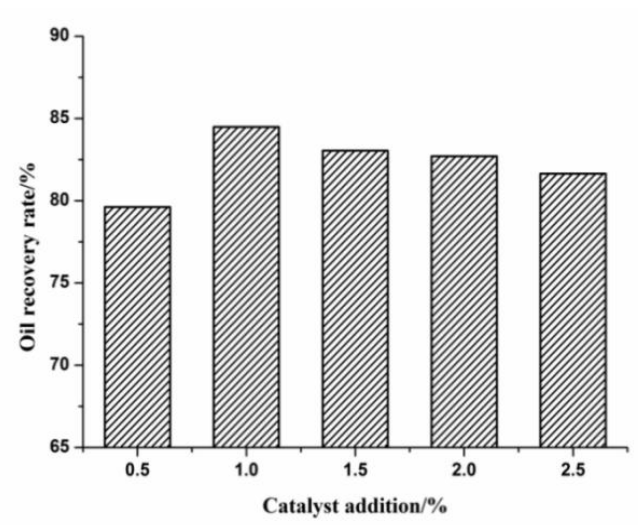

Fig. 9: The effect of the amount of catalyst on the oil recovery rate of the pyrolysis process.

of the amount of catalyst on the oil recovery rate of pyrolysis process was investigated.

From Fig. 9, the oil recovery rate increases with the increase of catalyst addition amount when the catalyst addition is between $0.5-1 \%$. When the amounts of catalysts are more than $1 \%$, the oil recovery rate has decreased. Considering the cost of the catalyst, when the amount of catalyst added was $1 \%$, the oil recovery rate is the highest.

Effect of catalyst on pyrolysis temperature of oily sludge: When the pyrolysis time was $4 \mathrm{~h}$, the heating rate was $10^{\circ} \mathrm{C} /$ min, the nitrogen flow rate was $100 \mathrm{~mL} / \mathrm{min}$ and catalyst quantity was $1 \%$, the effect of the pyrolysis temperature on the oil recovery rate of pyrolysis process was investigated.

It can be seen from Fig. 10 that in the process of sludge pyrolysis, the oil recovery rate without the catalyst and the optimum catalyst is different from the change of temperature. The pyrolysis process without catalyst added the maximum oil recovery at $450^{\circ} \mathrm{C}$, which was $76.06 \%$. With

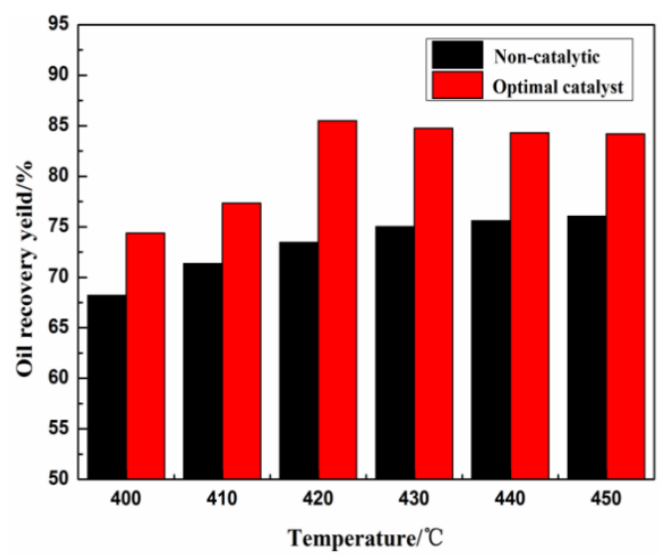

Fig. 10: The effect of pyrolysis temperature on the oil recovery rate of the pyrolysis process. the addition of a catalyst, the maximum oil recovery can reach $85.49 \%$ at $420^{\circ} \mathrm{C}$. The recovery rate of pyrolysis oil is significantly higher than that without catalyst and compared with non-catalyst, it can be reduced by $30^{\circ} \mathrm{C}$ when the maximum oil recovery rate is reached. When the temperature gradually increased, macromolecular organic compounds began to pyrolyse into some small molecules, oil recovery rate gradually increased as the temperature continues to rise, macromolecular pyrolysis reaction process with many intermediate products will occur secondary pyrolysis (Zheng 2013, Yang et al. 2014). This will lead to lower oil recovery rates. It is indicated that the catalyst has an obvious effect on the pyrolysis process.

Effect of catalyst on pyrolysis time of oily sludge: When the pyrolysis temperature was $420^{\circ} \mathrm{C}$, the heating rate $10^{\circ} \mathrm{C} /$ $\mathrm{min}$, the nitrogen flow rate $100 \mathrm{~mL} / \mathrm{min}$ and catalyst quantity $1 \%$, the effect of the pyrolysis time on the oil recovery rate of pyrolysis process was investigated.

From Fig. 11 it can see that the pyrolysis time is a balance factor of the pyrolysis of oily sludge, which also has a direct impact on the pyrolysis process. It can be seen from the figure that the recovery rate of pyrolysis oil increases first and then decreases with the extension of residence time. Without a catalyst, the oil recovery rate was $76.07 \%$ at $4 \mathrm{~h}$ pyrolysis time. After adding a catalyst, the oil recovery rate reached $85.82 \%$ at $3 \mathrm{~h}$ pyrolysis time. During the reaction, when the reaction stays for a short time, some of the sludge has not reached the current temperature of the full state of pyrolysis, and when the reaction time is too long, the oil occurred the secondary pyrolysis (Zhang 2016). Compared with the non-catalyst, it can be reduced by $1 \mathrm{~h}$ when the maximum oil recovery rate is reached. Catalyst has the obvious promoting effect on the pyrolysis reaction and increased the recovery rate of oil. The activation energy required for pyrolysis reaction

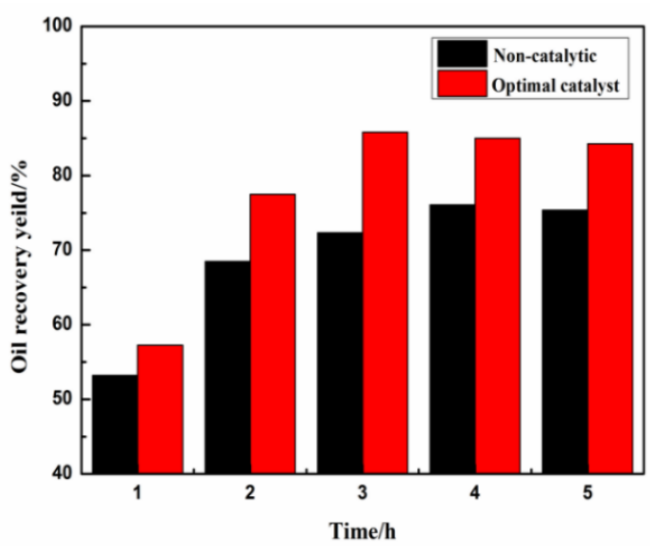

Fig. 11: The effect of pyrolysis time on the oil recovery rate of the pyrolysis process. 


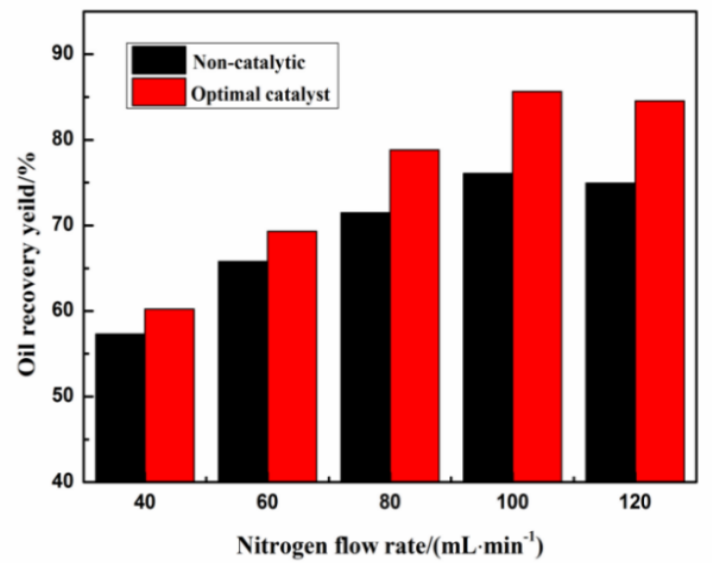

Fig. 12: The effect of nitrogen flow rate on catalytic pyrolysis of oily sludge.

is reduced, and the pyrolysis reaction time is shortened. It provides technical support for catalytic pyrolysis technology.

\section{Effect of catalyst on the nitrogen flow rate of oily sludge:} When the pyrolysis temperature was $420^{\circ} \mathrm{C}$, the pyrolysis time $3 \mathrm{~h}$, the heating rate $10^{\circ} \mathrm{C} / \mathrm{min}$ and catalyst quantity $1 \%$, the effect of nitrogen flow rate on the oil recovery rate of oily sludge was studied. The result is shown in Fig. 12.

It can be concluded that the oil recovery rate increases first, and then decreases with the increase of nitrogen flow rate. When the nitrogen flow rate under $100 \mathrm{~mL} \cdot \mathrm{min}^{-1}$, the oil recovery rate shows an increasing trend. Because part of the oil-water mixture produced in the pyrolysis cannot be taken out to the condensation system in time, and secondary cracking occurs. However, when the nitrogen flow rate is greater than $100 \mathrm{~mL} \cdot \mathrm{min}^{-1}$, the oil recovery rate is reduced. This is due to the excessive nitrogen flow rate causes the oil-water mixture generated during the pyrolysis process to be carried to the tail gas emission system with nitrogen (Liu 2016). Compared with the non-catalyst, the addition of $\mathrm{TiO}_{2}$ /bentonite(2) in the process of pyrolysis of oily sludge has an obvious effect in promoting the recovery rate of oil.

Effect of catalyst on the heating rate on of oily sludge: When the pyrolysis temperature was $420^{\circ} \mathrm{C}$, the pyrolysis time $3 \mathrm{~h}$, the nitrogen flow rate $100 \mathrm{~mL} / \mathrm{min}$ and catalyst quantity $1 \%$, the effect of the heating rate on the oil recovery rate of pyrolysis process was studied. The result is shown in Fig. 13

The Fig. 13 shows that when the heating rate is $10^{\circ} \mathrm{C} \cdot \mathrm{min}^{-1}$, the oil recovery rate reaches the maximum. At the low heating rate, it means that the pyrolysis time of oily sludge is prolonged under low temperature conditions so that the cracking rate of light components and heavy components in the sludge is slowed down. At the high heating rate, the light component evaporates quickly without sufficient pyrolysis and only the cracking of the heavy components occurs, so that the pyrolysis of oily sludge cannot be fully carried out (Yang et al. 2015). Compared with the noncatalyst, the addition of $\mathrm{TiO}_{2}$ /bentonite(2) in the process of pyrolysis of oily sludge has an obvious effect in promoting the recovery rate of oil.

\section{Analysis of Pyrolysis Products}

\section{Composition Analysis of the Liquid Phase of Pyrolysis Products}

It can be seen from Fig. 14 that after the addition of the catalyst, the content of heavy components in the pyrolysis oil decreases, and the content of light components increases, among them $\mathrm{C}_{16}-\mathrm{C}_{20}$ are the master components. In the process of pyrolysis of oily sludge, the catalyst was added to promote the cracking of heavy components in oily sludge,

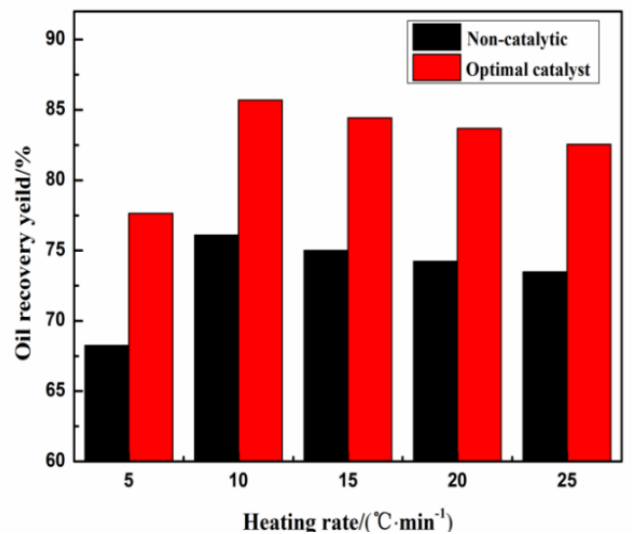

Fig. 13: The effect of the heating rate on the oil recovery rate of the pyrolysis process.

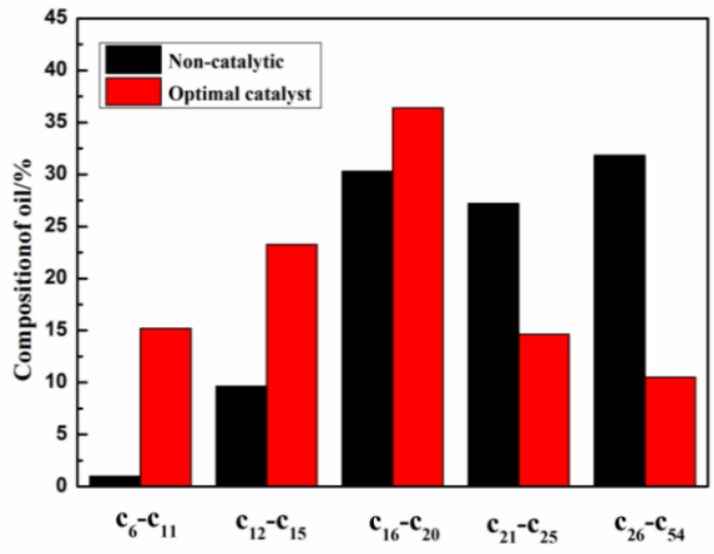

Fig. 14: Composition analysis of the liquid phase of pyrolysis products. 
which increased the content of light components in the recovered oil. It not only improves the recovery rate of pyrolytic oil but also improves the quality of the oil. Among the three catalysts: bentonite, $\mathrm{TiO}_{2}$ /bentonite(1) and $\mathrm{TiO}_{2}$ /bentonite(2), the catalytic effect of $\mathrm{TiO}_{2}$ /bentonite(2) is the best.

\section{Determination of Four Components of Pyrolysis Liquid Phase Products}

As can be seen from Table 4, compared with the non-catalyst, the content of aromatic hydrocarbons, colloids and bitumen in the four components of the pyrolysis liquid phase product with the catalyst is reduced, and the content of saturated hydrocarbons is significantly increased. It is indicated that the addition of catalyst promotes the further pyrolysis of oily sludge, especially the decomposition of heavy oil so that the heavy oil of pyrolysis oil is light.

\section{Morphology Analysis of Pyrolysis Residue}

The SEM analysis of optimum catalyst pyrolysis residue and raw mud pyrolysis residue are shown in Fig. 15 and Fig. 16. The EDS analysis of pyrolysis residue and raw mud pyrolysis residue are shown in Fig. 17 and Fig. 18. Compared with the raw mud pyrolysis residue, the optimal catalyst pyrolysis residue is porous, the porosity is increased, the particle accumulation is loose, the particles become smaller, and the particles are not found to be coked (Li et al. 2018). This provides a condition for the residue to act as a catalyst ( $\mathrm{Li}$ et al. 2018, Yang et al. 2018, Cheng et al. 2015).

\section{Specific Surface Area and Aperture Determination of Pyrolysis Residue}

It can be seen from Table 5 that the specific surface area of

Table 4: Analysis of four components of pyrolysis liquid phase products.

\begin{tabular}{|lllll|}
\hline Samples & Component/\% & & & \\
\cline { 2 - 5 } & Saturated hydrocarbon & Aromatic hydrocarbons & Glial & Asphaltene \\
\hline Non-catalyst & 18.65 & 32.61 & 1.95 & 9.73 \\
Optimum catalyst & 30.43 & 15.52 & 1.12 & 1.32 \\
\hline
\end{tabular}

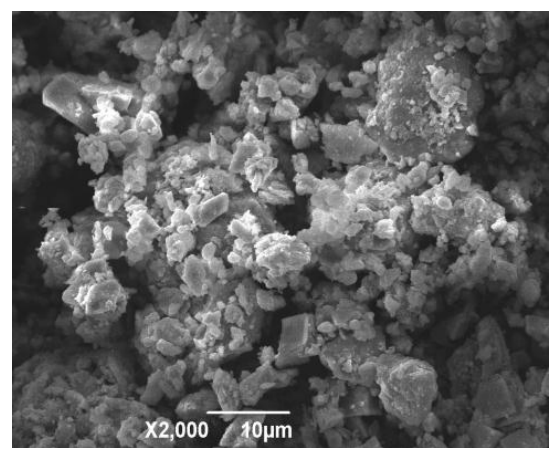

Fig. 15: SEM image of optimal catalyst.

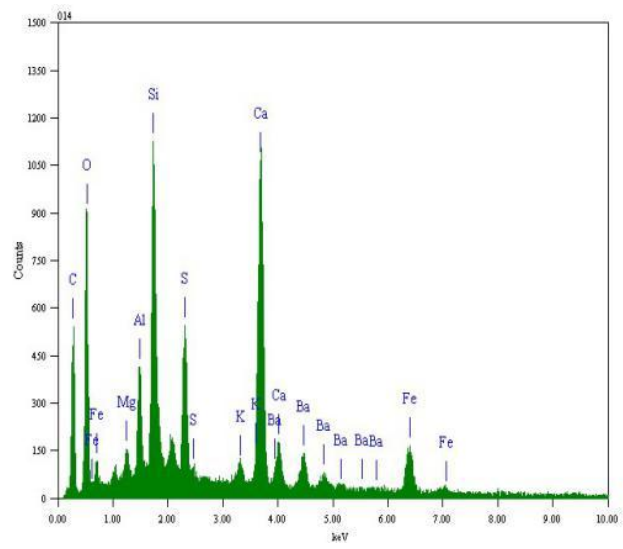

Fig. 17: EDS spectra of optimal catalyst.

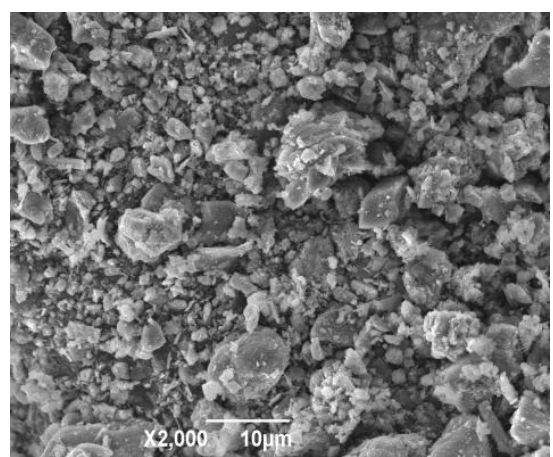

Fig. 16: SEM image of raw mud.

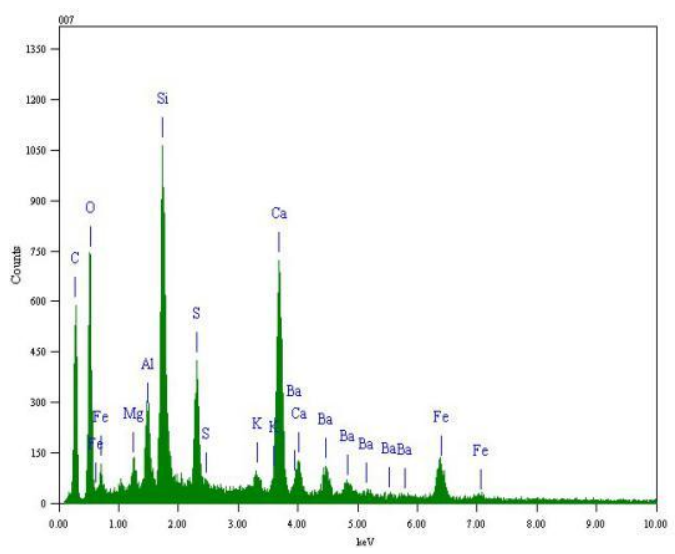

Fig. 18: EDS image of raw mud 
Table 5: Mesopore surface area and pore volume results of pyrolysis residue.

\begin{tabular}{|llll|}
\hline & $\mathrm{S}_{\text {mes }}\left(\mathrm{m}^{2} / \mathrm{g}\right)$ & $\mathrm{V}_{\text {mes }}\left(\mathrm{cm}^{3} / \mathrm{g}\right)$ & BJH average aperture $(\AA)$ \\
\hline Non- catalyst & 3.49 & 0.014 & 205.2 \\
Optimum catalyst & 4.24 & 0.02 & 167.5 \\
\hline
\end{tabular}

Table 6: Elemental analysis, oil content and heating value of pyrolysis residue.

\begin{tabular}{|lllllllll|}
\hline Samples & \multicolumn{9}{l|}{ Element composition $(\%)$} & & & \\
\cline { 2 - 8 } & $\mathrm{N}(\%)$ & $\mathrm{C}(\%)$ & $\mathrm{H}(\%)$ & $\mathrm{S}(\%)$ & $\mathrm{C} / \mathrm{N}$ & $\mathrm{C} / \mathrm{H}$ & Oil content/\% & $\mathrm{Calorific}$ value/(kJ $/ \mathrm{kg})$ \\
\hline Non- catalyst & 0.04 & 6.89 & 0.485 & 2.835 & 179.95 & 14.21 & 2.23 & 3176.55 \\
$\mathrm{TiO}_{2}$ /bentonite (2) & 0.19 & 8.34 & 0.49 & 2.67 & 56.97 & 14.51 & 2.02 & 2897.45 \\
\hline
\end{tabular}

the optimum catalyst pyrolysis residue is higher than that of raw mud pyrolysis residue, the specific surface area increased from $3.49 \mathrm{~m}^{2} / \mathrm{g}$ to $4.24 \mathrm{~m}^{2} / \mathrm{g}$. This provides a condition for the residue to act as a catalyst.

\section{Elemental Analysis, Oil Content and Calorific Value of Pyrolysis Residue}

According to Table 6, the content of $\mathrm{N}$ element in residue increases obviously after adding a catalyst, the content of $\mathrm{H}$ element decreases, the $\mathrm{C} / \mathrm{N}$ decreases, and the $\mathrm{C} / \mathrm{H}$ increases, which indicates that the catalyst can fix nitrogen and dehydrogenate during pyrolysis. The oil content of the residue without catalyst was $2.23 \%$, while the oil content of the residue was reduced to less than $2 \%$ after adding the catalyst, indicating that after adding the catalyst, more oil components were converted into the liquid phase and gas phase, thus oil content of the residue has reduced. The lower the oil content in the residue, the smaller the corresponding calorific value.

\section{CONCLUSIONS}

1. $\mathrm{A} \mathrm{TiO}_{2}$ /bentonite system with well-dispersed $\mathrm{TiO}_{2}$ particles in the bentonite was prepared by the sol-gel method. It was characterized that $\mathrm{TiO}_{2}$ was successfully loaded onto bentonite.

2. The effects of catalysts on different pyrolysis temperature, pyrolysis time, heating rate and nitrogen flow rate were obtained. The recovery rate of pyrolysis oil is significantly higher than that without catalyst and compared with non-catalyst, it can be reduced by $30^{\circ} \mathrm{C}$ when the maximum oil recovery rate is reached. Compared with the non-catalyst, it can be reduced by $1 \mathrm{~h}$ when the maximum oil recovery rate is reached.

3. This work shows the feasibility of introducing $\mathrm{TiO}_{2} /$ bentonite catalysts to sewage sludge for regulating pyrolysis and consequently both the yield of pyrolysis oil and the quality of pyrolysis oil were enhanced. The recovery rate was $8.1 \%$ higher than that without a catalyst.

\section{ACKNOWLEDGMENTS}

This work was supported by the Open Project Program of State Key Laboratory of Petroleum Pollution Control; and Shaanxi Youth Science and technology new star project (2017KJXX-49); and Scientific Research Program Funded by Shaanxi Provincial Education Department (Program No.18JS088); and Natural Science Basic Research Plan in Shaanxi Province of China (Program 2019JM-506)

\section{REFERENCES}

Agar, D. A., Kwapinska, M. and Leahy, J. J. 2018. Pyrolysis of wastewater sludge and composted organic fines from municipal solid waste: laboratory reactor characterisation and product distribution. Environmental Science and Pollution Research, 25(12): 1-9.

An, N., Ma, Y., Liu, J., Ma, H., Yang, J. and Zhang, Q. 2018. Enhanced visible-light photocatalytic oxidation capability of carbon-doped $\mathrm{TiO}_{2}$ via coupling with fly ash. Chinese Journal of Catalysis, 39(12): 1890-1900.

Botella, L., Sierra, M., Bimbela, F., Gea, G., Sánchez, J. L. and Gonzalo, A. 2016. Enhancement of biodiesel oxidation stability using additives obtained from sewage sludge fast-pyrolysis liquids. Energy \& Fuels, 30(1): 302-310.

Cao, L., Qu, Y., Xie, D. and Jing, C. 2011. Preparation and characterization of porous $\mathrm{TiO}_{2}$ with $\mathrm{La}_{2} \mathrm{O}_{3}$ load. Rare Metals, 30(1): 221-224.

Chen, J., Yao, N., Wang, R. and Zhang, J. 2009. Hydrogenation of chloronitrobenzene to chloroaniline over $\mathrm{Ni} / \mathrm{TiO}_{2}$ catalysts prepared by sol-gel method. Chemical Engineering Journal, 148(1): 164-172.

Cecílio, A. A., Pulcinelli, S. H., Santilli, C. V., Maniette, Y. and Silva, V. T. D. 2004. Improvement of the $\mathrm{Mo} / \mathrm{TiO}_{2}-\mathrm{Al}_{2} \mathrm{O}_{3}$ catalyst by the control of the sol-gel synthesis. Journal of Sol-Gel Science and Technology, 31(1-3): 87-93.

Cheng, S., Li, A. and Yoshikawa, K. 2015. High quality oil recovery from oil sludge employing a pyrolysis process with oil sludge ash catalyst. Int. J. Waste. Resour., 5(2): 176.

Folgueras, M. B., Alonso, M. and Díaz, R.M. 2013. Influence of sewage sludge treatment on pyrolysis and combustion of dry sludge. Energy, 55(1): 426-435.

Gong, Z., Wang, Z., Wang, Z., Du, A., Fang, P., Sun, Z. and Li, X. 2018. Study on pyrolysis of oil sludge with microalgae residue additive. The Canadian Journal of Chemical Engineering, 96(9): 1919-1925.

Hayhurst, A. N. 2013. The kinetics of the pyrolysis or devolatilisation of sewage sludge and other solid fuels. Combustion and Flame, 160(1): 138-144. 
Lin, B., Wang, J., Huang, Q. and Chi, Y. 2017. Effects of potassium hydroxide on the catalytic pyrolysis of oily sludge for high-quality oil product. Fuel, 200: 124-133.

Lin, B., Huang, Q., Ali, M., Wang, F., Chi, Y. and Yan, J. 2019. Continuous catalytic pyrolysis of oily sludge using U-shape reactor for producing saturates-enriched light oil. Proceedings of the Combustion Institute, 37(3): 3101-3108.

Liu, P., Zhang, Z., Jia, M., Gao, X. and Yu, J. 2015. ZSM-5 zeolites with different $\mathrm{SiO}_{2} / \mathrm{Al}_{2} \mathrm{O}_{3}$ ratios as fluid catalytic cracking catalyst additives for residue cracking. Chinese Journal of Catalysis, 36(6): 806-812.

Li, Y., Zhang, S., Yu, Q. and Yin, W. 2007. The effects of activated carbon support on the structure and properties of $\mathrm{TiO}_{2}$ nanoparticles prepared by a sol-gel method. Applied Surface Science, 253(23): 9254-9258.

Liu, J. P., Zhao, H., Song, X. L. and Li, X. L. 2009. Effects of calcination temperature on structure of titanium oxide photocatalyst. Inorganic Chemicals Industry.

Liu, X. Y., Yang, Y. Q. and Chen, H. J. 2011. Organic bentonite load $\mathrm{ZnO} / \mathrm{TiO}_{2}$ photodegradation catalyst development and performance. Chinese Journal of Spectroscopy Laboratory, 28(03): 1154-1157.

Liu, L. Z. 2016. Study on low temperature catalytic pyrolysis of oil sludge catalyst synthesis and application technology. Xi' an Shiyou University.

Li, J. L., Qu, C. T., Zhu, S. D., Fan, X. Y. and Zhu, Z. H. 2018. Characteristics and reutilization of pyrolytic residues of oily sludge: An overview. Materials review A: review papers, 32(17): 3023-3032.

Li, Y., Hu, H. J., Qu, C. T. and Yu, T. 2018. Influencing factors for catalytic pyrolysis of oily sludge and analysis of pyrolysis products. Modern Chemical Industry, (1): 15.

Mrayyan, B. and Battikhi, M. N. 2005. Biodegradation of total organic carbons (TOC) in Jordanian petroleum sludge. Journal of Hazardous Materials, 120(1-3): 127-134.

Méndez, A., Gascó, G., Freitas, M. M. A., Siebielec, G., Stuczynski, T. and Figueiredo, J. L. 2005. Preparation of carbon-based adsorbents from pyrolysis and air activation of sewage sludges. Chemical Engineering Journal, 108(1-2): 169-177.

Naqvi, S. R., Tariq, R., Hameed, Z., Ali, I., Naqvi, M., Chen, W. H. and Shahbaz, M. 2019. Pyrolysis of high ash sewage sludge: Kinetics and thermodynamic analysis using Coats-Redfern method. Renewable energy, 131: 854-860.

Shie, J. L., Lin, J. P., Chang, C. Y., Shih, S. M., Lee, D. J. and Wu, C. H. 2004. Pyrolysis of oil sludge with additives of catalytic solid wastes. Journal of Analytical and Applied Pyrolysis, 71(2): 695-707.

Shao, J., Yan, R., Chen, H., Yang, H. and Lee, D. H. 2010. Catalytic effect of metal oxides on pyrolysis of sewage sludge. Fuel Processing Technology, 91(9): 1113-1118.

Tang, S., Zheng, C., Yan, F., Shao, N., Tang, Y. and Zhang, Z. 2018. Product characteristics and kinetics of sewage sludge pyrolysis driven by alkaline earth metals. Energy, 153: 921-932.

Tang, S., Tian, S., Zheng, C. and Zhang, Z. 2017. Effect of calcium hydroxide on the pyrolysis behavior of sewage sludge: reaction characteristics and kinetics. Energy \& Fuels, 31(5): 5079-5087.

Wang, Z., Wang, J., Xie, L., Zhu, H. and Shu, X. 2019. Influence of the addition of cotton stalk during co-pyrolysis with sewage sludge on the properties, surface characteristics, and ecological risks of biochars. Journal of Thermal Science, 28(4): 755-762.

Wang, J., Sun, C., Lin, B. C., Huang, Q. X., Ma, Z. Y., Chi, Y. and Yan, J. H. 2018. Micro-and mesoporous-enriched carbon materials prepared from a mixture of petroleum-derived oily sludge and biomass. Fuel Processing Technology, 171: 140-147.

Wang, J., Liu, T. L., Huang, Q. X., Ma, Z. Y., Chi, Y. and Yan, J. H. 2017. Production and characterization of high quality activated carbon from oily sludge. Fuel Processing Technology, 162: 13-19.

Wang, H., Jia, H., Wang, L. and Chen, H. 2015. The catalytic effect of modified bentonite on the pyrolysis of oily sludge. Petroleum Science and Technology, 33(13-14): 1388-1394.

Wang, W. L., Liu, B. J. and Zeng, X. J. 2008. Catalytic cracking of $\mathrm{C}_{4}$ hydrocarbons on ZSM-5 molecular sieves with low $\mathrm{SiO}_{2} / \mathrm{Al}_{2} \mathrm{O}_{3}$ molar ratio. Acta Physico-Chimica Sinica, 24(11): 2102-2107.

Wu, X., Yin, S., Dong, Q., Guo, C., Li, H., Kimura, T. and Sato, T. 2013. Synthesis of high visible light active carbon doped $\mathrm{TiO}_{2}$ photocatalyst by a facile calcination assisted solvothermal method. Applied Catalysis B: Environmental, 142: 450-457.

Xiao, H. M. 2012. Study on catalytic pyrolysis characteristics and kinetics of paper making sludge. Journal of Zhaoqing University, 33(02): 28-32.

Yang, J., Xu, X., Liang, S., Guan, R., Li, H., Chen, Y. and Hou, H. 2018. Enhanced hydrogen production in catalytic pyrolysis of sewage sludge by red mud: thermogravimetric kinetic analysis and pyrolysis characteristics. International Journal of Hydrogen Energy, 43(16): 7795-7807.

Yao, K. S., Hsu, J. J. and Chang, C. Y. 2012. Study on the photocatalytic degradation of wastewater under the optimal preparation of the activated carbon supported $\mathrm{TiO}_{2}$ thin film. In: Advanced Materials Research, 356: 313-317, Trans Tech Publications Ltd.

Yang, X., Wang, X., Zhao, B. and Li, Y. 2014. Simulation model of pyrolysis biofuel yield based on algal components and pyrolysis kinetics. Bioenergy Research, 7(4): 1293-1304.

Yu, X. D., Zhou, Y. J. and Yang, S. C. 2017. Preparation and adsorption capacity of oxytetracycline hydrochloride by nano titania loaded organic bentonite. Chinese Journal of Environmental Engineering.

Yang Z. L. 2012. Study on preparation and catalytic organic reaction of modified bentonite catalyst. Qufu Normal University.

Yahya, N. Y. and Ngadi, N. 2016. Effect of calcination temperature on catalyst surface area of $\mathrm{Ca}$ supported $\mathrm{TiO}_{2}$ by sol-gel method for biodiesel production. In: Applied Mechanics and Materials, 818: 219-222, Trans Tech Publications Ltd.

Yang, P. H., Wei, J. and Qu, C. T. 2015. Vacuum pyrolysis of oil sludge from Yancheng oilfield. Environmental Engineering, 10: 22.

Yang, J., Xu, X., Liang, S., Guan, R., Li, H., Chen, Y. and Hou, H. 2018. Enhanced hydrogen production in catalytic pyrolysis of sewage sludge by red mud: Thermogravimetric kinetic analysis and pyrolysis characteristics. International Journal of Hydrogen Energy, 43(16): 7795-7807.

Zhao, B., Jin, J., Li, S., Liu, D. and Yang, H. 2019. Co-pyrolysis characteristics of sludge mixed with Zhundong coal and sulphur contaminant release regularity. Journal of Thermal Analysis and Calorimetry, 1.

Zhao, Z., Fan, J., Liu, S. and Wang, Z. 2009. Optimal design and preparation of titania-supported CoPc using sol-gel for the photoreduction of $\mathrm{CO}_{2}$. Chemical Engineering Journal, 151(1-3): 134-14.

Zhang, M., Huang, G. H., Hu, G. Y. and Zhao, H. J. 2009. Geochemical study on oil-cracked gases and kerogen-cracked gases (i)experimental simulation and products analysis. Science in China, 52(1 Supplement), 1-9.

Zhu, P. F., Liu, M., Zhu, T. J. and Song, C. 2012. Preparation and characterization of iron-doped $\mathrm{TiO}_{2} /$ bentonite photocatalyst. Chinese Journal of Spectroscopy Laboratory.

Zheng, Y. Y. 2013. Research on composition of gases and liquids obtained from different pyrolysis conditions of sewage sludge. Harbin Institute of Technology.

Zhang, J. D. 2016. Research on three phase products in sludge pyrolysis process. Harbin Institute of Technology. 